\title{
Process Design of Virgin Coconut Oil (VCO) Production Using Low-Pressure Oil Extraction
}

\author{
Patricia Janelle Ferrer ${ }^{1}$, Vanessa Ferl Quilinguen ${ }^{1}$, Jeremiah Rosario ${ }^{1}$, and Lola Domnina Pestaño ${ }^{1,2 *}$ \\ ${ }^{1}$ Chemical Engineering Department, Faculty of Engineering, University of Santo Tomas \\ ${ }^{2}$ Research Center for the Natural and Applied Science, University of Santo Tomas \\ España Boulevard 1015 Manila, THE PHILIPPINES
}

\begin{abstract}
Virgin coconut oil (VCO) has become one of the most prominent high-value coconut product in coconut producing countries because of its versatility. This research attempts to design a fresh-dry process based on the Low-Pressure Oil Extraction Method for the production of VCO to reduce the settling time of the oil after extraction, that usually takes 1-2 weeks. Different parameters, such as drying temperature, centrifuge speed, and centrifugation time were varied and analysed. Three mathematical models were examined to describe the drying behaviour of the grated coconut meat at 65,70 , and $75^{\circ} \mathrm{C}$ using a tray dryer. A VCO production fresh-dry process based on the Low-Pressure Oil Extraction Method was developed through the employment of a centrifuge. The modified method lessens the settling time while still producing standard quality VCO. As predicted by the Laplace Transform Model, the shortest time for the comminuted coconut meat to reach a moisture content of $11 \%$ at which oil from nuts can be extracted using low pressure is at 29.07 minutes using a tray dryer. The best setting of VCO production using the modified method is at a drying temperature of $70^{\circ} \mathrm{C}$ and at $2700 \mathrm{RPM}$ and 60 minutes of centrifugation as it produced the clearest oil with a yield of $92.84 \% \mathrm{v} / \mathrm{v}$ and a recovery of $18.43 \%$. The produced VCO was tested for free fatty acid (FFA), moisture and volatile matter, colour, peroxide value, and iodine value, and the results are $0.03 \%, 0.11 \%$, OR/0.3Y, 0, and 5.77, respectively, which all passed the Philippine National Standards for VCO.
\end{abstract}

\section{Introduction}

The purest type of coconut oil, virgin coconut oil (VCO), was introduced to the world market at the end of the $20^{\text {th }}$ century. It is considered one of the products of great value derived from the fresh coconut [1]. VCO, the clear, high value oil resulting from the fresh and mature kernel of coconut (Cocos nucifera L.), is obtained through mechanical and natural means, with or without the use of heat, without undergoing chemical refining, bleaching or deodorizing, which does not lead to alteration or transformation of the natural characteristics of oil [2]. It is now gaining a worldwide popularity because of its wide range of applications in medicine, food, cosmetics and the like [3].

VCO processing technologies can be generally categorized into fresh-dry process and fresh-wet process. The term fresh-wet is for the VCO process in which the VCO is obtained from the coconut milk by a variety of means after it has been extracted from freshly comminuted coconut kernel. The term fresh-dry on the other hand, is for the VCO process where VCO is obtained directly from the fresh coconut kernel which requires drying of the kernel in comminuted form before the extraction of oil [1].

Under the fresh-dry technologies is the low pressure oil extraction method. This method is common among micro- and village-scale industries and works on the principle that oil from seeds or nuts can be extracted using low pressure at about 460 psi provided that the moisture content of the material is within the range of $10-13 \%[3]$.

This process, however, requires at least two weeks of settling time to separate the fine particles of dried kernel from the extracted oil. A centrifuge, which is commonly used for emulsion breaking of coconut milk in fresh-wet VCO processing technologies [4] may be utilized to greatly lessen the settling time while still producing VCO which passes the quality standards set by the Philippine National Standards (PNS) for VCO, as well as the Asian and Pacific Coconut Community (APCC). Other factors,

*Corresponding author: lbpestano@ust.edu.ph 
such as drying temperature, centrifugation speed, and centrifugation time may also affect the quality of the VCO produced [5].

The general objective of this study is to lessen the settling time of the low pressure oil extraction method of VCO fresh-dry production through the employment of a centrifuge as replacement to the traditional settling. Different parameters such as drying temperature, centrifugation speed, and centrifugation time were varied and analyzed in order to obtain the optimum setting for the process design.

Specifically, the objectives of the study are:

(1) To design a VCO production fresh-dry process based on the low-pressure oil extraction method that greatly lessens the settling time through the employment of a centrifuge while still producing standard quality VCO; and

(2) to determine the optimum drying temperature and drying time to achieve $11 \% \mathrm{MC}$ of the comminuted coconut meat, centrifugation speed, and centrifugation time, and the optimum setting that will yield the fastest process and the highest quality of product.

\section{Methods}

\subsection{Raw material collection and preparation}

Fresh de-husked coconuts of 10 to 12 months of age were obtained from Oriental Mindoro, Philippines. The coconuts used in this research were of similar sizes, brown in color and did not have haustorium. The nuts were labelled Nut 1 to Nut 10 . The fresh mature coconuts were split and comminuted through a manual/motor grater.

\subsection{The equipment used}

The equipment used in the experimentation were the tray dryer, fabricated manual press and the digital centrifuge DSC-301SD. The tray dryer was readily available in the Unit Operations Laboratory (Lab 4A) of the Chemical Engineering Department in the Roque Ruaño building of University of Santo Tomas, while the digital centrifuge used was from the UST College of Education, located at the Food Technology Laboratory Annex, $2^{\text {nd }}$ floor of the UST Albertus Magnus building. The 4-ton hydraulic jack manual press was fabricated and bought from an external supplier.

\subsubsection{Manual press}

The hydraulic manual press used in the experiment was pre-fabricated. The manual press' frames and body were made from aluminum while the parts that come in direct contact with the grated coconut meat, such as the tray and the roof, were made of stainless steel. A bottle-type hydraulic jack with a maximum allowable load of 4 tons, manufactured by Hoyoma, Japan Power Tools, was the source of the hydraulic system of the manual press. Figure 1 shows the dimensions and the different views of the fabricated hydraulic jack manual press.

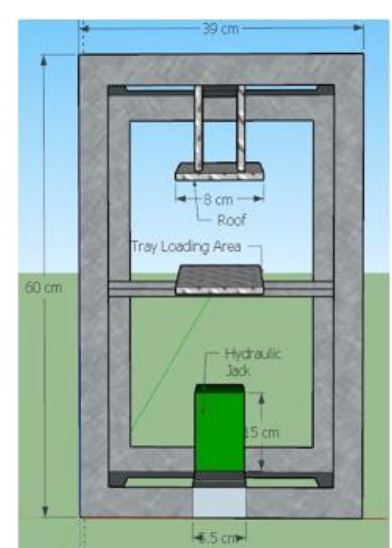

(a)

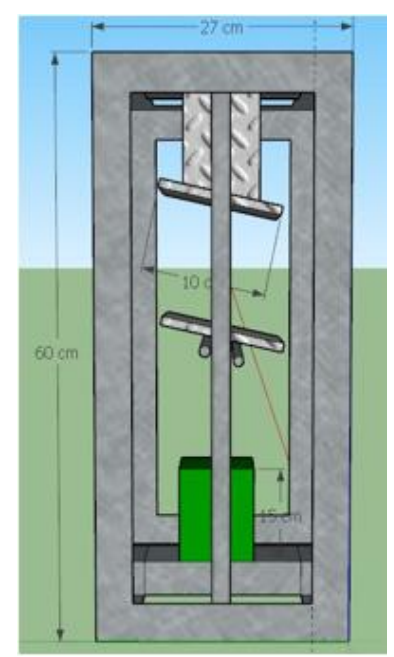

(b)

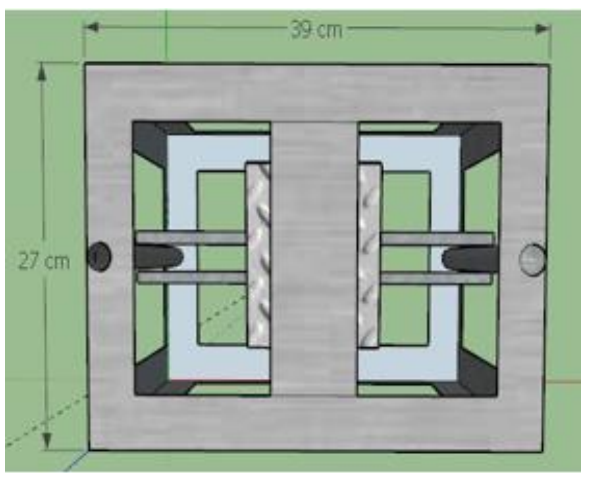

(c)

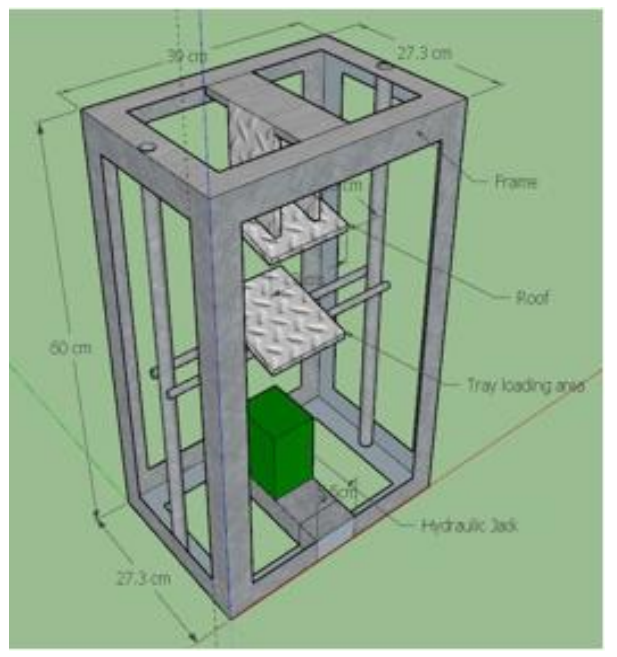

(d)

Fig. 1. Fabricated hydraulic manual press: (a) Front view, (b) Right-side view, (c) Top view, (d) Isometric view. 


\subsubsection{Digital Centrifuge}

The digital centrifuge used was Digital Centrifuge Model DSC 301SD developed by Digi system Laboratory Instrument Inc. It has a maximum RPM of 4000 and can contain 4 units of $50 \mathrm{~mL}$ corning tubes per run. A specifications sheet of the necessary information is given in Table 1.

Table 1. Specifications sheet of Digital Centrifuge Model DSC-301SD

\begin{tabular}{|c|c|}
\hline Speed & $300-4000 \mathrm{RPM}$ \\
\hline Motor & DC Motor \\
\hline Rotor & SB-071550 \\
\hline Rotor Type & $45^{\circ}$ Angle \\
\hline Capacity & $\begin{array}{c}16 \times(5-7 \mathrm{~mL}) \\
12 \times(10-15 \mathrm{~mL}) \\
4 \times(50 \mathrm{~mL})\end{array}$ \\
\hline Weight & $\begin{array}{c}\text { N.W. } 19 \mathrm{Kg} \\
\text { G.W. } 21 \mathrm{Kg}\end{array}$ \\
\hline Overall & $500 \mathrm{~mm} \times 390 \times 290$ \\
Dimensions & $\mathrm{AC} 110 \mathrm{~V}$ \\
Power Supply & $50 / 60 \mathrm{~Hz}$ \\
\hline
\end{tabular}

\subsection{Mass balance}

For each nut, the shell, water, and grated coconut meat were weighed using a precision balance with accuracy of $0.01 \mathrm{~g}$. Per cent composition of the materials for each nut was determined. Mass balance was performed to account for the losses. The average values for the ten nuts were calculated.

\subsection{The Drying Experiment}

The grated coconut meat was spread evenly and thinly on a tray with a surface area of 182.88 square centimeters and a thickness of not more than $1 \mathrm{~cm}$. The grated coconut meat was heated at temperatures, $65-75^{\circ} \mathrm{C}$ at $5^{\circ} \mathrm{C}$ intervals every $5 \mathrm{~min}$ until constant weight is obtained. Before beginning the experiments, the tray dryer system was preheated in order to achieve a desirable steady state condition of temperature.

Weighing of the dried grated coconut meat was done using a precision balance with an accuracy of $0.01 \mathrm{~g}$. Drying experiments for each temperature were conducted in triplicate.

\subsubsection{Mathematical Modelling}

The parameters that will be used in the modeling are the moisture ratio (MR) and the drying rate (R). The $M R$ during drying was calculated using Equation 1:

$$
M R=\frac{M-M_{e}}{M_{i}-M_{e}}
$$

where $\mathrm{M}, \mathrm{Mi}$ and $\mathrm{Me}$ are the $\mathrm{MC}$, in $\mathrm{g}$, at any time $\mathrm{t}$, the initial $\mathrm{MC}$ and the equilibrium $\mathrm{MC}$, respectively. The $\mathrm{R}$ was calculated from the experimental data using Equation 2:

$$
R=-\frac{W_{S}}{A} \frac{d \bar{X}^{\prime}}{d t}
$$

where Ws is the weight in g, of the dry solid, A is the surface drying area in $\mathrm{m}^{2}, \mathrm{X}^{\prime}$ is the bulk MC and $\mathrm{t}$ is time. Equation 2 can be rearranged and integrated. The integral form Equation 3 was used to obtain the drying time.

$$
\int_{0}^{t} d t=-\frac{W_{S}}{A} \int_{\bar{X}_{1}^{\prime}}^{\bar{X}_{2}{ }_{2}} \frac{d \bar{X}^{\prime}}{R}
$$

The drying data (MR vs. t) at 65,70 and $75^{\circ} \mathrm{C}$ were fitted into the three mathematical models: Page Model, Laplace Transform Model and Non-linear Decomposition Model. Drying is a complex process and as a means to simplify the analysis of the drying kinetics of grated coconut meat, empirical expressions are used [6]. Mathematical modeling using thin-layer drying equations are used to evaluate drying time of products based from experimental data. Models are often used to study the variables involved in the process, predict drying kinetics of the product and optimize the operating parameters and circumstances [7]. The values of the correlation coefficient, $\mathrm{R}^{2}$, for the Page and Non-linear Decomposition Model, the time constant, tau, $\tau$ for the Laplace Transform Model and the total error for the three models were computed. The selection of the best model to describe the drying behavior of the grated coconut meat will be based on the least total error and the goodness of fit of a model.

The Page Model was successfully used to describe the drying characteristics of some agricultural products $[8,9$, $10]$. The Page Model $[11,12]$ that was used in this study was derived by linearizing the $\mathrm{R}$ equation shown in Equation 4.

$$
M R=a e^{-k t^{n}}
$$

Eq. (5) is the linearized form of Eq. (4).

$$
M R=\ln a-k t^{n}
$$

The Laplace Transform Model and Non-Linear Decomposition Model are used for prediction of the behavior of a system as reduction of moisture proceeds until it reaches equilibrium [13]. The Laplace Transform Model was derived from a material balance of the system in the experiment. The general material balance states that the input minus the output of the system is equal to rate of accumulation as shown in Equation 6. 


$$
M_{i}-M_{o}=\tau \frac{d M}{d t}
$$

Equation 6 is then formulated to its Laplace Transform Model [14], integrated and simplified forming Equation 7 used in modeling the drying rate characteristics of the grated coconut meat.

$$
M=M_{f}-M_{f} e^{-\frac{t}{\tau}}+M_{i} e^{-\frac{t}{\tau}}
$$

The Non-linear Decomposition Model is based on the differential equation for batch decomposition as given in Equation 8.

$$
\frac{1}{C^{n-1}}=\frac{1}{C_{o}{ }^{n-1}}+(n-1) k t
$$

The determination of the MR is represented by the concentration [15] and is represented below in Equation 9.

$$
M R=\sqrt[n-1]{\frac{M R_{o}^{n-1}}{1+(n-1) k t M R_{o}{ }^{n-1}}}
$$

\subsubsection{Determination of Drying Time to Attain 11\% $M C$}

The drying time needed to attain the needed $11 \% \mathrm{MC}$ was determined through Lagrange interpolation. This method generates nth-order polynomials that pass through $(n+1)$ points. These polynomials attempt to produce interpolation values of increased accuracy by assuming a curvature in the relationship of the data. Its general equation is represented by Equation 10. The three versions are Equations 11-13.

The Lagrange interpolation:

$$
f_{n}(x)=\sum_{i=0}^{n} L_{i}(x) f\left(x_{i}\right)
$$

First-Order version:

$$
f_{1}(x)=\frac{x-x_{1}}{x_{0}-x_{1}} f\left(x_{0}\right)+\frac{x-x_{0}}{x_{1}-x_{0}} f\left(x_{1}\right)
$$

Second-Order version:

$$
\begin{aligned}
f_{1}(x)= & \frac{\left(x-x_{1}\right)\left(x-x_{2}\right)}{\left(x_{0}-x_{1}\right)\left(x_{0}-x_{2}\right)} f\left(x_{0}\right)+\frac{\left(x-x_{0}\right)\left(x-x_{2}\right)}{\left(x_{1}-x_{0}\right)\left(x_{1}-x_{2}\right)} f\left(x_{1}\right) \\
& +\frac{\left(x-x_{0}\right)\left(x-x_{1}\right)}{\left(x_{2}-x_{0}\right)\left(x_{2}-x_{1}\right)} f\left(x_{2}\right)
\end{aligned}
$$

Third-Order version:

$$
\begin{aligned}
& f_{3}(x)=\frac{\left(x-x_{1}\right)\left(x-x_{2}\right)\left(x-x_{3}\right)}{\left(x_{0}-x_{1}\right)\left(x_{0}-x_{2}\right)\left(x_{0}-x_{3}\right)} f\left(x_{0}\right)+\frac{\left(x-x_{0}\right)\left(x-x_{2}\right)\left(x-x_{3}\right)}{\left(x_{1}-x_{0}\right)\left(x_{1}-x_{2}\right)\left(x_{1}-x_{3}\right)} f\left(x_{1}\right) \\
& +\frac{\left(x-x_{0}\right)\left(x-x_{1}\right)\left(x-x_{3}\right)}{\left(x_{2}-x_{0}\right)\left(x_{2}-x_{1}\right)\left(x_{2}-x_{3}\right)} f\left(x_{2}\right)+\frac{\left(x-x_{0}\right)\left(x-x_{1}\right)\left(x-x_{2}\right)}{\left(x_{3}-x_{0}\right)\left(x_{3}-x_{1}\right)\left(x_{3}-x_{2}\right)} f\left(x_{3}\right)
\end{aligned}
$$

\subsection{Combined low pressure oil extraction and centrifugation method}

The dried grated coconut meat was subjected under low pressure oil extraction using a fabricated manual press. A clean cheesecloth was used to hold the dried grated coconut meat together and to filter the undesired solid particles from the extract. The extracted crude coconut oil was collected in corning tubes in preparation for the final method which was the centrifugation method. A digital centrifuge (DSC-301SD) was used to speed up the settling time and to separate the foots or the fine kernel particles entrained in the oil, from the desired liquid.
Specific parameters such as the centrifugation speed and centrifugation time were varied occasionally to determine its effect on the resulting product. For the centrifuge speed - 2000 RPM and 2700 RPM were utilized, due to the limitations of the said equipment used. Centrifugation time was varied for each centrifugation speed using 20, 40, and 60 minutes. The centrifugation method was carried out using fresh samples of extracted crude coconut oil for each time and speed. After centrifugation, decantation was done to obtain the VCO, which was the clear top-most layer of the corning tube after centrifugation. Figure 2 shows the flowchart of the modified and improved low-pressure oil extraction method. 


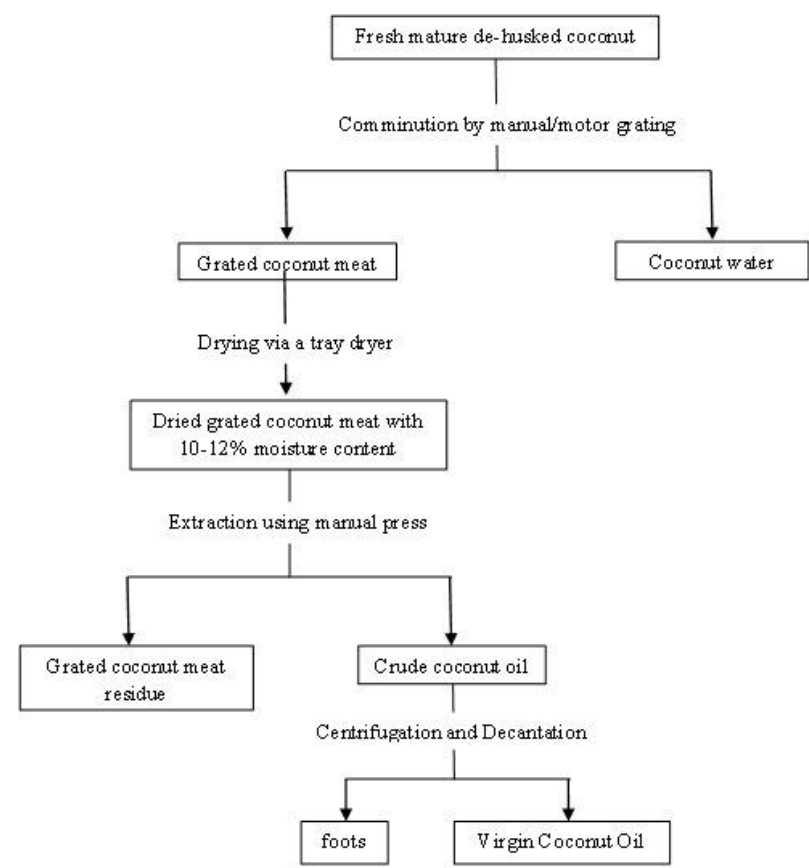

Fig. 2. Flowchart of low pressure oil extraction method for the production of $\mathrm{VCO}$

\subsection{Quality testing}

The resulting VCO was tested for specific parameters such as average yield per coconut, color, peroxide number, iodine value, moisture and volatile matter, and presence of free fatty acids (FFA). The extracted oil samples were brought to the Philippine Coconut Authority (PCA) for the testing of said parameters. The tests were done at the Research and Development department, Laboratory Services Division of PCA. VCOs from different parameter alterations of numerous trials were tested and compared. The tests were done at the ambient temperature, $25^{\circ} \mathrm{C}$.

\section{Results and Discussion}

\subsection{Coconut Mass Balance}

The composition and corresponding per cent by weight composition of each nut were calculated. From this data, average values were determined. For an average weight of 1374.01 grams, 520.07 grams coconut water, 312.21 grams shell and 517.27 grams grated coconut meat peel were accounted. The mass balance was done to estimate the oil recovery per coconut and to check the consistency of the weights of the coconuts used in this process.
Matured coconut has more meat, resulting to higher residue yield.

An average de-husked coconut used in this process, weighing at least 1,300 grams, contained at least $22.72 \%$ shell, $37.85 \%$ water, and $37.65 \%$ meat by weight and accounting for $1.78 \%$ losses. The losses can be attributed to the spillage of coconut water and the fragments of grated coconut meat which were not collected during comminution. Figure 3 shows the average composition of the parts of the 10 coconuts.

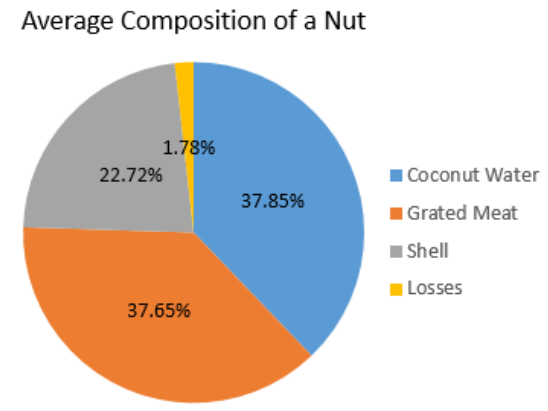

Fig. 3. The average composition (Ave. wt. $=1374 \mathrm{~g}$ ) of a nut

\subsection{Analysis of the Mathematical Models of the Drying of Grated Coconut Meat}

The MR data were fitted into the two models. The results, namely, value of the correlation coefficient, $\mathrm{R}^{2}$, for the Non-Linear Decomposition Model, the time constant, tau, $\tau$ for the Laplace Transform Model and the total error for the three models were recorded and are shown in Table 2. The best results based on the least total error were shown by the Laplace Transform Model at the three temperatures studied. The Laplace Transform Model yielded notable accuracy, precisely modeling the data series of grated coconut meat and predicting its future behavior. Using visual inspection, the Laplace Transform Model also gave the best fit as shown in Fig. 4. Hence, the Laplace Transform Model may be assumed to represent the drying behavior of grated coconut meat. Similar findings were reported for the air-drying kinetics of thin slices of coconut meat [14]. Earlier research works reported that the Page Model represent the drying kinetics of coconut meat slices [16, 17]. Figure 4 shows the experimental drying kinetic data as they are fitted with the simulated models at $70^{\circ} \mathrm{C}$ drying temperature. 
Table 2. Summary of Results

\begin{tabular}{|c|c|c|c|c|c|c|c|c|}
\hline \multirow{2}{*}{ Temp. } & \multicolumn{3}{|c|}{ Page Model } & \multicolumn{3}{c|}{$\begin{array}{c}\text { Non-linear Decomposition } \\
\text { Method }\end{array}$} & \multicolumn{2}{c|}{$\begin{array}{c}\text { Laplace } \\
\text { Transform Model }\end{array}$} \\
\cline { 2 - 9 } & $\boldsymbol{n}$ & $\boldsymbol{R}^{2}$ & Total Error & $\boldsymbol{n}$ & $\boldsymbol{R}^{2}$ & Total Error & $\boldsymbol{\tau}$ & Total Error \\
\hline $65^{\circ} \mathrm{C}$ & 1.4 & 0.9787 & 0.0349 & 0.7 & 0.9994 & 0.00328 & 897 & $3.50 \mathrm{E}-07$ \\
\hline $70^{\circ} \mathrm{C}$ & 1.5 & 0.9928 & 0.0109 & 0.75 & 0.9464 & 0.16354 & 479 & $6.50 \mathrm{E}-07$ \\
\hline $75^{\circ} \mathrm{C}$ & 1.8 & 0.9864 & 0.0274 & 0.7 & 0.9951 & 0.01758 & 267 & $4.20 \mathrm{E}-06$ \\
\hline
\end{tabular}
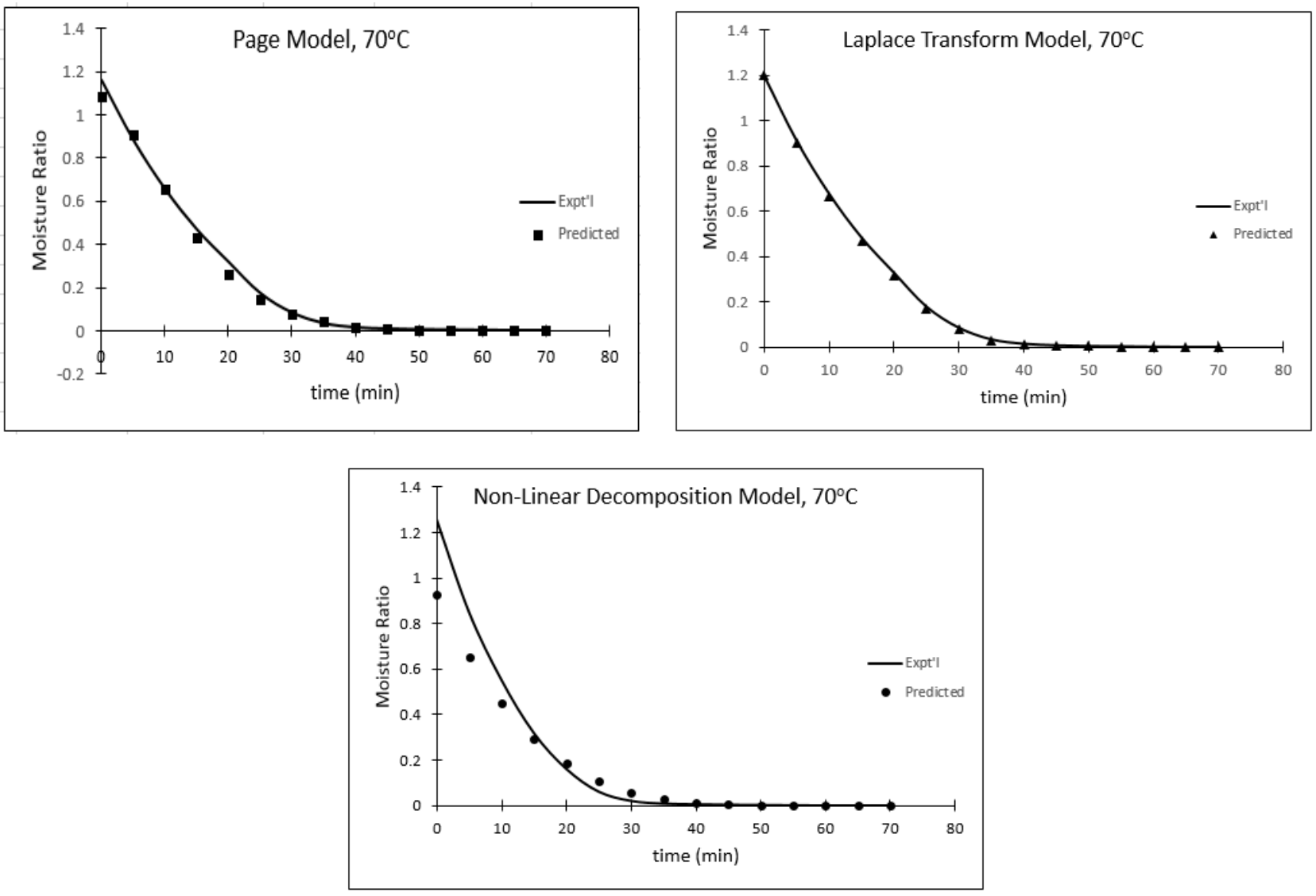

Fig. 4. Comparison of the experimental and predicted values of $\mathrm{MR}$ vs. time at $70^{\circ} \mathrm{C}$ using the three models

Table 3. Calculated drying time at different treatment temperatures as predicted by the Laplace Transform Model

\begin{tabular}{|c|c|c|c|}
\hline \multirow{2}{*}{ Trial No. } & \multicolumn{3}{|c|}{ Temperature } \\
\cline { 2 - 4 } & $\mathbf{6 5}^{\mathbf{}} \mathbf{C}$ & $\mathbf{7 0}^{\circ} \mathbf{C}$ & $\mathbf{7 5}^{\circ} \mathbf{C}$ \\
\hline 1 & $39.26 \mathrm{~min}$ & $29.70 \mathrm{~min}$ & $30.51 \mathrm{~min}$ \\
\hline 2 & $54.90 \mathrm{~min}$ & $34.00 \mathrm{~min}$ & $27.84 \mathrm{~min}$ \\
\hline 3 & $54.61 \mathrm{~min}$ & $35.57 \mathrm{~min}$ & $34.05 \mathrm{~min}$ \\
\hline
\end{tabular}

\subsection{Determination of the Drying Time using the Lagrange Method of Interpolation}

The drying time for the grated coconut meat to reach the desired MC of $11 \%$ at which oil from nuts can be extracted using low pressure [3]. The Laplace Transform Model was used to predict the optimum drying time at which the MC of the grated coconut meat will be $11 \%$. The drying time was computed using Lagrange interpolation. The average drying time to reach $11 \% \mathrm{MC}$ from the initial range of $54-56 \%$ was $49.59,33.09$ and 30.80 min at drying temperatures of 65,70 and $75^{\circ} \mathrm{C}$, respectively. Table 3 shows the calculated heating time as 
predicted by the Laplace Transform Model. A shorter heating time at $70^{\circ} \mathrm{C}$ was utilized to attain a $11 \% \mathrm{MC}$ in the grated coconut meat.

\subsubsection{Observation of the grated cocount meat after drying at different temperatures.}

The grated coconut meat that was dried at $65^{\circ} \mathrm{C}$ was too milky that would require a longer centrifugation time, which may cause undesired heating due to the centrifugal force. On the other hand, when $75^{\circ} \mathrm{C}$ was used as a drying temperature, the grated coconut meat was burnt or scorched. Burnt coconut meat causes yellow oil, which does not pass the standards for VCO.

\subsection{Statistical analysis of the computed drying Time using the best fit Mathematical Model}

The best condition for drying the grated coconut meat was at a drying time of 29.70 minutes at $70^{\circ} \mathrm{C}$, which was computed using the Laplace Transform Model and the Lagrange Method of Interpolation. Table 4 shows the statistical analysis of the drying data gathered at $70^{\circ} \mathrm{C}$, using a $95 \%$ confidence level.

The standard deviation and the confidence limits were evaluated using Microsoft Excel. Based on the table, for the drying of grated coconut meat at $70^{\circ} \mathrm{C}$, the results were $95 \%$ confident that the drying time needed to achieve $11 \%$ moisture content ranges from 29.65 to 36.53 minutes.

Table 4. Statistical analysis of the best drying temperature at $95 \%$ confidence level $(\alpha=0.05)$

\begin{tabular}{|c|c|c|c|c|c|c|}
\hline Trial & $\begin{array}{c}\text { Drying } \\
\text { Time, } \text { min }\end{array}$ & Ave. & $\begin{array}{c}\text { Std. } \\
\text { Dev. }\end{array}$ & $\begin{array}{c}\text { Conf. } \\
\text { Int. }\end{array}$ & LL & UL \\
\hline 1 & 29.70 & & & & & \\
\cline { 1 - 2 } 2 & 34.00 & \multirow{2}{*}{33.09} & 3.04 & 3.44 & 29.65 & 36.53 \\
\hline 3 & 35.57 & & & & & \\
\hline
\end{tabular}

\subsection{Analysis of data from the centrifugation process}

Centrifugation time and centrifugation speed were both varied to obtain the optimum condition that will provide the greatest amount of oil yield and greatest initial quality of VCO upon organoleptic evaluation. Two variations of centrifuge speed, 2000 and 2700 RPM, were used. Centrifugation time was varied for each centrifugation speed using 20, 40, and 60 minutes. Figure 5 shows the plot for $\% \mathrm{VCO}$ yield against centrifugation time for both speeds. The process was done under ambient temperature of $25^{\circ} \mathrm{C}$.

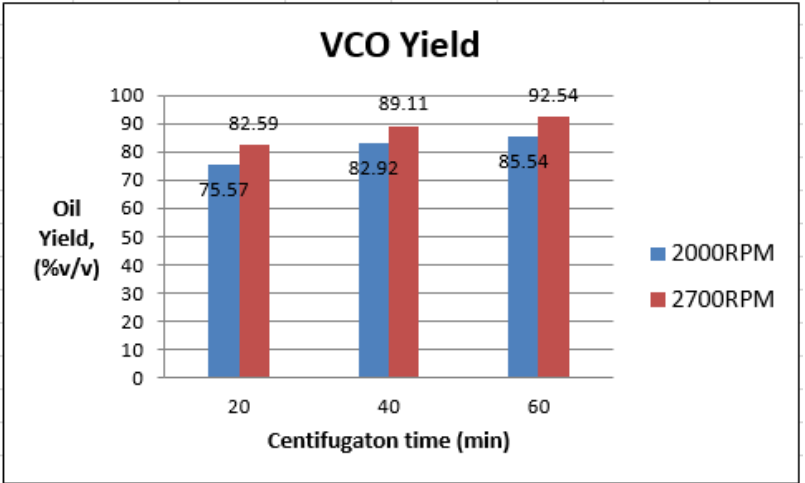

Fig. 5. VCO yield with the effect of centrifugation time for 2000 RPM and 2700 RPM

Based on Figure 5, the highest oil yield occurs at 2700 RPM with 60 minutes of centrifugation time at 92.84 $\mathrm{v} / \mathrm{v} \%$. Also, upon organoleptic inspection, the clarity of oil increases as centrifugation time and centrifugation speed increases, yielding the clearest oil at 60 minutes of centrifugation for both 2000 and 2700 RPM. This observation is explained by the fact that increasing the centrifuge speed results in increasing the rate of sedimentation and consequently increases the separation of the two phases [4]. Also during centrifugation process, heat is generated by the centrifugal rotation. Density and viscosity, which are temperature dependent properties are altered. When temperature increases, viscosity and density decreases. As a result, the foots and fine particles will settle faster at higher temperatures [18].

\subsubsection{Calculation of Oil Recovery}

With the density of the virgin coconut oil at room temperature known as $0.903 \mathrm{~g} / \mathrm{mL}$, based on literature [5], the oil recovery for the optimum setting was determined using Equation 14.

$$
\text { Oil Re covery }=\frac{\text { wt. of VCO re covered }}{\text { wt.of coconut meat used }} \times 100
$$

For each full tray loaded, the average volume of crude coconut oil obtained from 5 trials was $75.20 \mathrm{~mL}$, with $69.82 \mathrm{~mL}$ being the VCO obtained, based from the data from the oil yield. The average weight of each full tray from 5 trials was $342.15 \mathrm{~g}$. The oil recovery of the designed process was computed to be $18.43 \%$, while the oil recovery of the traditional low pressure oil extraction is $25 \mathrm{~kg} / 100 \mathrm{~kg}$ meat or $25 \%$.

The amount of VCO that can be obtained from a single coconut can be computed by Equation 15 .

Amount of VCO per nut $=\left(\frac{\% \text { Re covery }}{100}\right)($ wt. of meat $/$ nut $)$

The weight of grated coconut meat was determined by the mass balance in the previous part of the experiment, 
with a value of $517.27 \mathrm{~g}$. Knowing those values, the weight of oil that can be extracted from a single coconut was computed to be $95.33 \mathrm{~g}$ or $105.57 \mathrm{~mL}$.

\subsection{Results of Quality Testing}

The VCO sample produced at the best condition, 29.70 minutes of drying at $70^{\circ} \mathrm{C}$, and 60 minutes of centrifugation at $2700 \mathrm{RPM}$, was brought to the Laboratory Services Division of the Philippine Coconut Authority and was tested for the FFA, moisture and volatile matter, color, peroxide value, and iodine value. Table 5 shows the result of the laboratory tests, with the Philippine National Standards for Virgin Coconut Oil alongside.

Table 5. Results of quality testing of the sample VCO $\left(70^{\circ} \mathrm{C}\right.$ drying time, 2700 RPM and 60 minutes of centrifugation)

\begin{tabular}{|l|c|c|}
\hline \multicolumn{1}{|c|}{ Parameters } & Results & Standards \\
\hline FFA (Lauric) & $0.03 \%$ & $0.20 \% \max$. \\
\hline Moisture and Volatile Matter & $0.11 \%$ & $0.20 \% \max$. \\
\hline Color: (5 1/4" cell) Red/Yellow & $0 \mathrm{R} / 0.3 \mathrm{Y}$ & Colorless \\
\hline Peroxide Value (meq $/ \mathrm{Kg}$ ) & 0 & $3 \mathrm{max}$. \\
\hline Iodine Value & 5.77 & $4.11-11.0$ \\
\hline
\end{tabular}

Based on the quality testing results, all values of each tested parameter passed the Philippine National Standards for VCO. The color test result suggests that there were 0 red color and 0.3 yellow color detected in the produced VCO sample. The detected yellow value was very small and insignificant; thus, the color does not affect the quality of the VCO produced. Favorably, there was no detection of the red color in the sample, otherwise, the produced VCO sample will already be affirmed as a refined, bleached, and deodorized (RBD) oil, not VCO.

There is no standard set by the Philippine Bureau of Product Standards for the iodine values of virgin coconut oil, however, based on the study of Dayrit and his colleagues on the Standards for Essential Composition and Quality Factors of Commercial Virgin Coconut Oil and its Differentiation from RBD Coconut Oil and Copra Oil in 2007, the Codex Alimentarius standard for coconut oil range for iodine value is 6.3 to 10.6 [19], while the Asian and Pacific Coconut Community (APCC) standards for VCO range from 4.1 to 11.0 , making the iodine value of the produced VCO sample in this study pass the both the Codex standard and the APCC standard.

Both the results for the FFA and peroxide value were within the limits set by the Philippine National Standards for VCO. These two parameters are the most critical chemical properties to be met for an oil to be classified as a VCO. VCO is the purest form of coconut oil containing very low amount of FFA and having a low peroxide value.

Naturally, FFAs are recorded to be low for vegetable oils. A high amount of FFA would give the oil an unpleasant taste, which is undesirable for a VCO that has a fresh and raw coconut taste. In addition, an FFA of above $0.5 \%$ will cause itchiness in the throat when consumed [20]. This would mean that a change in the oil's composition has taken place and it is corrosive which can be dangerous to the health.

Peroxide value on the other hand is the measurement of the extent of an oil's rancidity. Rancidity denotes the spoilage of a food which results from oil or fat deterioration. VCO has a low content of unsaturated fatty acids making its tendency to be rancid poor. High peroxide value would mean that the oil is unstable and already contaminated [21].

\section{Conclusions and Recommendations}

\subsection{Conclusions}

A VCO production fresh-dry process based on the lowpressure oil extraction method was developed through the employment of a centrifuge. As predicted by the Laplace Transform Model, the shortest time for the comminuted coconut meat to reach a moisture content of $11 \%$ is at 29.07 minutes using a tray dryer. The best setting of VCO production using the modified method is at a drying temperature of $70^{\circ} \mathrm{C}$ and at $2700 \mathrm{RPM}$ and 60 minutes of centrifugation. The developed method lessens the settling time while still producing standard quality VCO.

The authors would like to express their deepest gratitude to the University of Santo Tomas Food Technology Department, College of Education, for allowing us to use the equipment in their laboratory.

\section{References}

1. D. D. Bawalan, Process Manual for Virgin Coconut Oil, its Products and By-products for Pacific Island Countries and Territories (2011)

2. M. Arumugam, M. Raman, \& K. Eagappan, Int. J. of Pharmacy \& Pharmaceutical Sci. 186-190 (2014)

3. D. D. Bawalan, \& K. R. Chapman, Virgin Coconut Oil Production Manual for Micro- and VillageProcessing (2006)

4. S. Panpanya, \& S.P. Pathaveerat, Study and design manufacture of virgin coconut oil by centrifuge method (2012)

5. Y. Wong, \& H. Hartina, Or. J. of Chem. 30(1), 237245 (2014)

6. Clary C, Farid M, Fasina O, Hui Y, Noomhorm A, \& Welti-Chanes J. Food Drying Science and Technology: Microbiology, Chemistry, Applications. In: Lypez-Malo A \& Rios-Casas L Solar Assisted Drying of Foods, p. 84. (Lancaster: DEStech Publications Inc.( 2008) 
7. Belessiotis VG \& Karathanos VT. Agr. Eng. Resour. 355- 361 (1991)

8. Singh S, Raina GS, Bawa AS, \& Saxena DG.. Drying Technol. 24:1487-1497 (2006)

9. Doymaz I \& Ismail O. Food Bioprod. Process; 89:31-38 (2011)

10. Hassan-Beygi SR, Aghbashlo M, Kinamehr MH, \& Massad J. 23:129-135 (2009).

11. Agrawal YC \& Singh RC. Thin layer drying studies on short grain rough rice (ASAE Paper No. 773531. MI, U.S.A.: St. Joseph (1977)

12. Zhang Q \& Litchfield JB. Drying Technol. 9:383395 (1991)

13. Charbonnel C, Ghoul M, Guiga W, \& Ioannou I. Food and Bioproducts Processing Frozen mirabelle plum drying: Kinetics, modeling and impact on biochemical properties. (2010)

14. Pestaño LB.]. In: Third International Conference on Advances in Applied Science and Environmental Engineering (ASEE 2015) (USA: CInstitute of Research Engineers and Doctors). ISBN: 978-163248-055-2 (2015)

15. Jose WI \& Pestaño LB. J. Adv. Agr. Technol; 3(1):58-62 (2016)

16. Akoy EOM. Int. Food Res. J. 21(5): 1911-1917 (2014)

17. Goyal RK, Kingsly ARP, Manikantan MR, \& Ilyas SM. J. of Biosystems Eng.; 95(1):43- 49 (2006)

18. C. G. Khoo, A. Nour, \& A. H. Nour, Production of Virgin Coconut Oil (VCO) by Centrifuge Method (2011)

19. F. M. Dayrit et al. Philippine Journal of Science 136 (2): 119-129 (2007)

20. A. Albao, Coco Wonder. Retrieved from http://www.cocowonder.com.ph/index.php/healthbenefitsof-cocont-cacao/how-to-choose-top-qualityvco (1969)

21. O. Ojeh, Effects of refining on the physical and chemical properties of cashew kernel oil. J Fats Oils Technology (1981) 